\title{
Influence of climate change and hydroclimate variability on the impact of coal resource development on runoff
}

\author{
F.H.S. Chiew ${ }^{1}$, G. Fu ${ }^{2}$, D.A. Post ${ }^{1}$, Y. Zhang ${ }^{1}$, B. Wang ${ }^{1}$ and N.R. Viney ${ }^{1}$ \\ ${ }^{1}$ CSIRO Land and Water, Black Mountain, Canberra \\ ${ }^{2}$ CSIRO Land and Water, Floreat, Perth \\ Email:francis.chiew@csiro.au
}

\begin{abstract}
There have been a number of proposals to further develop coal seam gas and coal resources in eastern Australia. These developments may have an impact on water resources and the environment. The Australian Commonwealth Scientific and Industrial Research Organisation (CSIRO), in partnership with the Department of Environment and Energy, the Bureau of Meteorology and Geoscience Australia, have undertaken a series of "Bioregional Assessments" to assess the potential impacts of coal seam gas and coal mining development on water resources and water dependent assets such as wetlands and groundwater bores.

This paper investigates the sensitivity of the bioregional assessment results to climate change and hydroclimate variability, using the Gloucester subregion as an example. Specifically, the paper quantifies (i) the relative impact of coal mining development versus impact from potential climate change, (ii) the modelled impact of additional coal mining development (relative to "baseline" development) for different plausible climate futures, and (iii) the influence of hydroclimate variability (sequencing of future hydroclimate time series, particularly when the mine footprint is largest) on the modelled impact of additional coal mining development.

The results for the Gloucester subregion indicate that the impact of climate change on runoff can be considerably greater than the impact of coal mine development. However, the difference in the modelled impact of additional coal resource development relative to the baseline for a given climate future is relatively small, but not insignificant. The sequencing of hydroclimate series (hydroclimate variability), particularly the rainfall when the mine footprint is largest, significantly influences the modelled maximum additional coal resource development impact, and much more so than the future mean annual rainfall. If the rainfall is high in the period when the mine footprint is largest, the modelled maximum impact on volumetric and high flow hydrological variables will be higher, and the modelled maximum impact on low flow hydrological variables will be lower.

The results suggest that detailed analysis of coal resource development impact where proposed development is large should take into account climate change and hydroclimate variability. The relative and combined impact (which can enhance or compensate) from climate change and coal resource development should be modelled, as well as the range of possible rainfall sequencing (stochasticity and uncertainty) when the mine footprint is large.
\end{abstract}

Keywords: Cumulative impact, coal resource development, climate change, hydroclimate variability, hydrological modelling, Bioregional Assessments 


\section{INTRODUCTION}

There have been a number of proposals to further develop coal seam gas and coal resources in eastern Australia. These developments may have an impact on water resources and the environment. The Australian Commonwealth Scientific and Industrial Research Organisation (CSIRO), in partnership with the Department of Environment and Energy, the Bureau of Meteorology and Geoscience Australia, have undertaken a series of "Bioregional Assessments" to assess the potential impacts of coal seam gas and coal mining development on water resources and water-dependent assets such as wetlands and groundwater bores. The Bioregional Assessments have been carried out for six bioregions, and subregions within these bioregions. There are five components in the Bioregional Assessments: contextual information; model-data analysis; impact analysis; risk analysis; and outcome synthesis. The Bioregional Assessments method is described in Barrett et al. (2013) and the results for the different regions are reported in technical reports, research papers and online (http://www.bioregionalassessments.gov.au).

This paper investigates the sensitivity of the bioregional assessment results to climate change and hydroclimate variability, using the Gloucester subregion as an example. Specifically, the paper quantifies (i) the relative impact of coal mining development versus impact from potential climate change, (ii) the modelled impact of additional coal mining development (relative to "baseline" development) for different plausible climate futures, and (iii) the influence of hydroclimate variability (sequencing of future hydroclimate time series, particularly when the mine footprint is largest) on the modelled impact of additional coal mining development.

Section 2 describes the method used to model the impact of coal mining development on runoff. The impact of coal mining development in the context of climate change is presented and discussed in Section 3 . The impact of coal mining development in the context of hydroclimate variability is presented and discussed in Section 4. The results and implications are then summarised in Section 5.

\section{MODELLING THE IMPACT OF COAL MINING DEVELOPMENT ON RUNOFF}

Figure 1 shows the Gloucester subregion (in the North Sydney Basin), the locations of proposed coal seam gas and coal mining development, and the 30 receptor or stream nodes where the modelling results are reported. The surface water modelling for the Gloucester subregion is described in detail in Zhang et al. (2016). The brief description here focuses mainly on the surface water modelling carried out to explore the relative impact of coal mining development and climate change and hydroclimate variability.

Daily runoff is first modelled for $0.05^{\circ}(\sim 5 \mathrm{~km})$ grid cells across the region. The modelling is carried out using the Australian Water Resources Assessment Landscape (AWRA-L) model (Vaze et al. 2013). The same model parameters are used to model runoff across the entire region, with the model calibrated to best reproduce the observed daily streamflows at 16 largely unimpaired locations or catchments. Specifically, an automatic optimisation routine is used to find the set of parameter values that maximise the sum of Nash-Sutcliffe efficiency of daily runoff at the 16 gauged locations. Like most rainfall-runoff modelling in temperate regions with reasonably plentiful gauged streamflow data, the runoff in the region is reasonably well simulated.

The daily climate data used for the modelling come from the Bureau of Meteorology $0.05^{\circ}$ gridded climate data product (http://www.bom.gov.au/climate/averages/climatology/gridded-data-info/gridded-climatedata.shtml). The ninety years of daily time series climate data from 1921-2012 are used as inputs (i.e. the same daily climate sequence) to model runoff for the "future" over 2013-2102. Daily runoff at the 30 nodes is calculated as the aggregation of runoffs from all the grid cells (or part of grid cells) that contribute to the catchment area.

The modelled runoff is then reduced by the impact of the "mine footprint" in detaining surface runoff and preventing its entry to the natural stream network. The mine footprint includes the entire area disturbed by mine operations, pits, roads, spoil dumps, water storages and infrastructure. The mine footprint areas change over the lifetime of the mine operations. As new parts of the lease become active, the footprint increases. As mined parts of the lease are rehabilitated and the runoff returned to natural drainage, the footprint decreases. There are three coal mines proposed in the Gloucester subregion and their combined impact over time, expressed as percentage reduction in daily modelled runoff at Node 14, is shown in Figure 2. The impact is shown for Node 14 because the mine impact is largest here, and subsequent discussions will focus on the impact at Node 14 (Figure 1).

Figure 2 shows two modifications or reductions to the modelled "natural" runoff: for a baseline condition that includes all coal mines commercially producing as of December 2012; and for coal resource development pathway (CRDP) defined as a future with coal mines in the baseline as well as those that are expected to begin commercial production after December 2012. The impact of additional coal resource development (ACRD) is 
defined as the impact from CRDP minus the impact from Baseline. The largest mine footprint impacting Node 14 occurs in the year 2026 .

The modelling results for two hydrological variables are presented and discussed. The first variable is annual runoff, which reflects the volume of available water. The second variable reflects low flows, and is defined as the number of days in the year when daily runoff is below the $5^{\text {th }}$ percentile daily runoff value (this will be referred to as 'low flow days'). The $5^{\text {th }}$ percentile daily runoff is estimated from the modelled 2013-2102 runoff series (90 years) with no mining development. Analysis of the modelling results therefore gives a time series of 90 values corresponding to the 90 years, of both annual runoff and low flow days. A 90 year time series of ACRD impact is then calculated as the difference between the values in the CRDP simulation and the Baseline simulation. The maximum impact is then defined as the maximum absolute value in the ACRD impact time series. The maximum ACRD impact is influenced mainly by the mine footprint (therefore this generally occurs around 2026 for Node 14 when the mine footprint in largest), and also by the runoff in the different years. The maximum annual runoff impact is presented as the percentage reduction in annual runoff divided by the mean annual runoff. The maximum 'low flow' impact is presented as the increase in number of days with runoff below the $5^{\text {th }}$ percentile. The maximum ACRD impact on annual runoff and on low flow at the 30 nodes are shown in Figures 3 and 4 respectively. The plots show significant ACRD impact at Node 14 (maximum annual runoff impact of $11 \%$ and maximum low flow impact of 9 days) and little impact elsewhere.
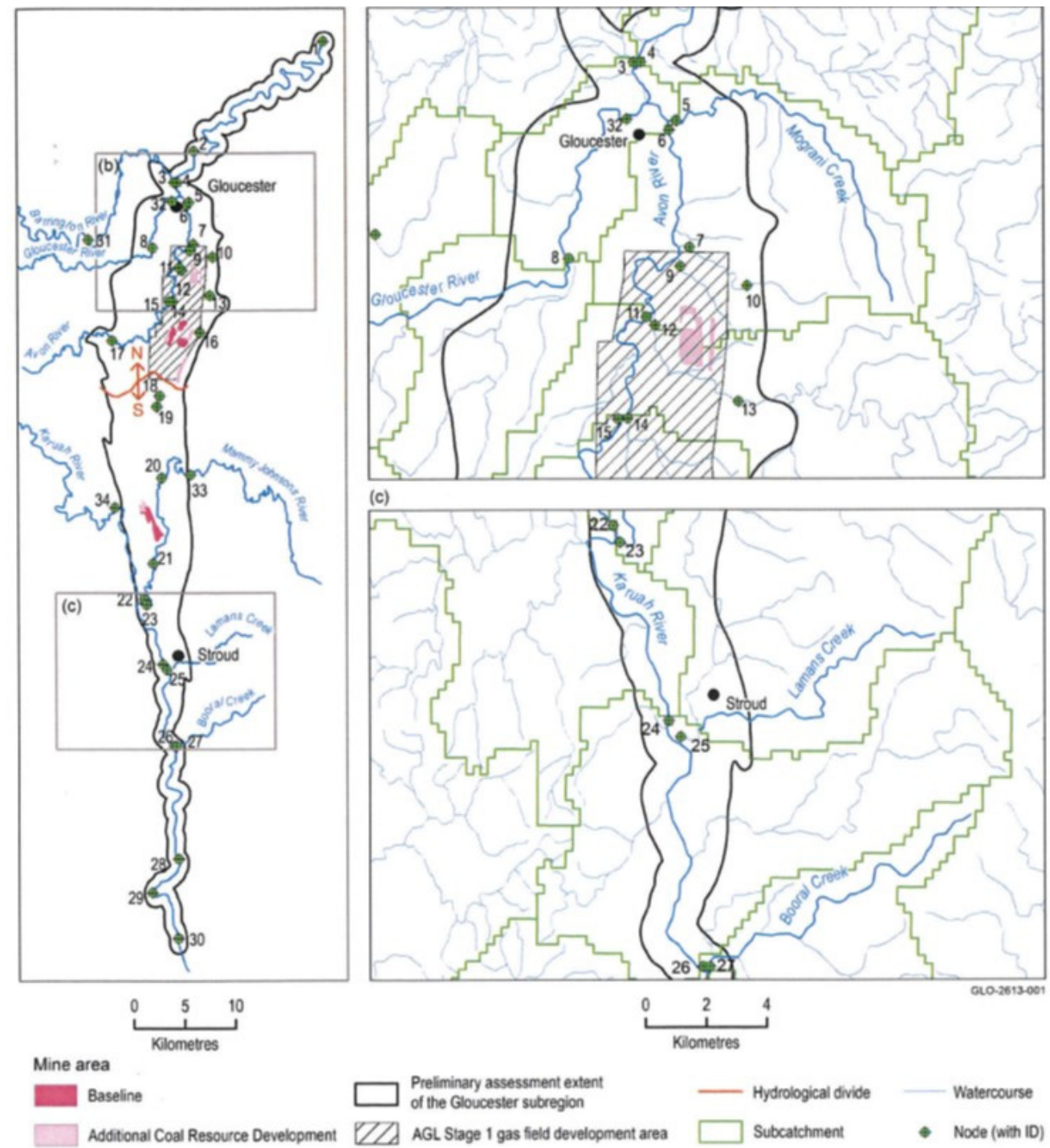

Figure 1. Map of study area showing the Gloucester subregion, locations of proposed coal seam gas and coal mining development, and 30 receptor or stream nodes where the modeling results are reported (from Zhang et al., 2016). 
There are several differences in the simplified modelling here compared to the Bioregional Assessments modelling for the Gloucester subregion described in Zhang et al. (2016). First, the modelling here considers only runoff reduction from the footprint of coal mining development. The impact of groundwater extraction and groundwater dewatering from coal seam gas development on baseflow is not modelled. This impact is relatively small in the Gloucester subregion (Zhang et al. 2016), but can be very significant (particularly on low flow characteristics) in other bioregions. Second, the uncertainty in model parameterisation and in the assumptions used to quantify the impact of coal mining development is not considered here. Third, the modelling here uses the 1923-2012 climate series to represent 90 years of 2013-2102 climate, whilst the Bioregional Assessments concatenate the 30-year 1983-2012 climate series to represent the 2013-2102 climate. Fourth, the Bioregional Assessments present results for a much larger

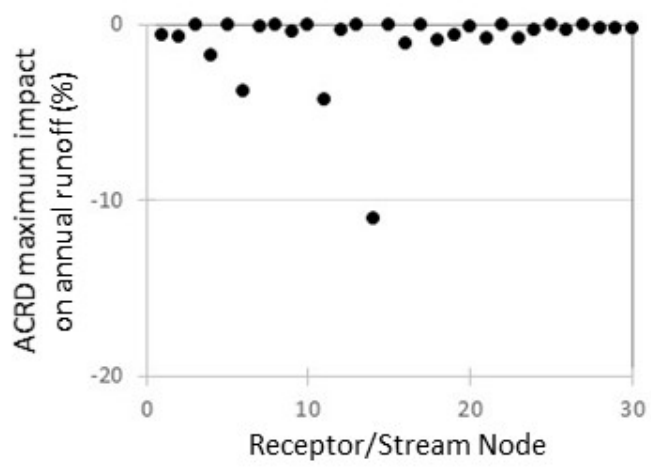

Figure 3. ACRD maximum impact on annual runoff (presented as percentage reduction in absolute annual runoff divided by mean annual runoff). number of hydrological variables. Nevertheless, the modelling here gives results that are very similar to the bioregional assessment modelling for the Gloucester subregion, and facilitates the exploration of the impact of coal mining development in the context of climate change and hydroclimate variability.

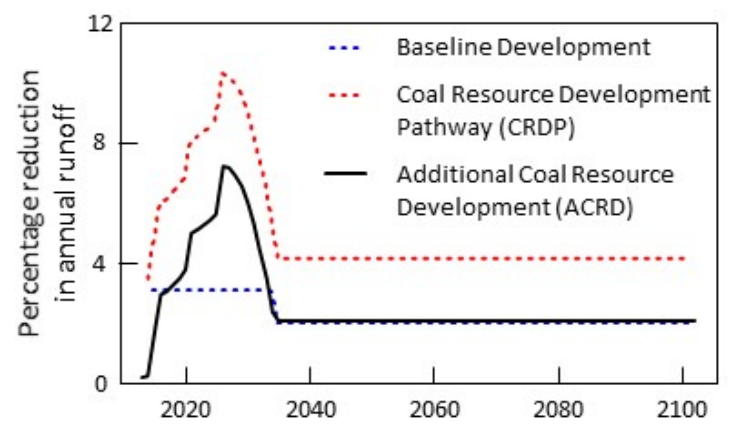

Figure 2. Reduction in annual runoff at Node 14 from coal mine footprint.

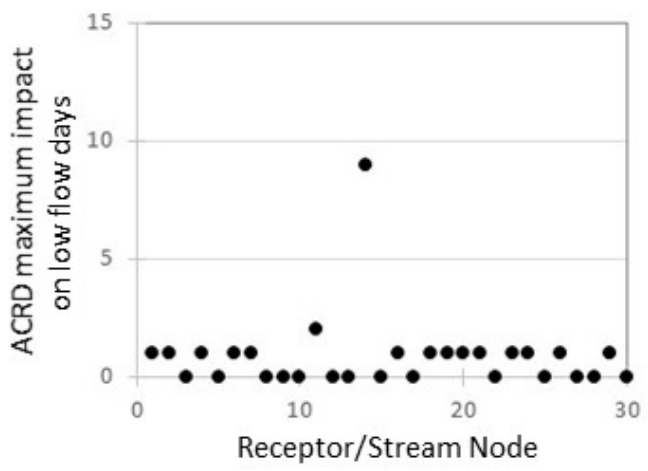

Figure 4. ACRD maximum impact on low flow (presented as increase in number of days with runoff less than the $5^{\text {th }}$ percentile value).

\section{IMPACT OF COAL MINING DEVELOPMENT IN THE CONTEXT OF CLIMATE CHANGE}

The sensitivity of runoff to future climates is explored here by scaling the 2013-2102 rainfall series used in the modelling above. The entire 90 years of daily rainfall is scaled by the same factor. Scaling factors of $-10 \%$, $-5 \%,+5 \%$ and $+10 \%$ are used. For context, the median projected change in annual rainfall by 2046-2075 for RCP8.5 (high representative concentration pathway or emission scenario) for the region from 42 global climate models used in the IPCC AR5 (Intergovernmental Panel on Climate Change Fifth Assessment Report) is -2\%, with a $10^{\text {th }}$ and $90^{\text {th }}$ percentile range of $-13 \%$ to $+12 \%$.

The results for annual runoff and for low flow are presented in Figures 5 and 6 respectively. The plots show the maximum impact (as defined above) for the scaled rainfall series (reflecting plausible changes in future mean annual rainfall) relative to the original 2013-2102 rainfall series with no mining development. As expected, the percentage change in rainfall is amplified as a percentage change in runoff (Chiew 2006, Chiew et al. 2009). The 5\% scaling led to a maximum annual runoff impact of $20-30 \%$ at most receptor or stream nodes, and the $10 \%$ scaling led to a maximum annual runoff impact of more than $50 \%$ at most nodes (Figure 5). The potential climate change impact is therefore significantly greater than the ACRD maximum annual runoff impact of $11 \%$ at Node 14 and close to zero elsewhere (Figure 3 ). For low flow, the $-5 \%$ scaling led to a maximum impact of 10-30 more low flow days (number of days when daily runoff is below the $5^{\text {th }}$ percentile value) at most nodes, and the $-10 \%$ scaling led to a maximum impact of 30-50 more low flow days at most nodes (Figure 6). The potential climate change impact on low flow is therefore also significantly greater than the ACRD maximum low flow impact of 9 days at Node 14 and close to zero elsewhere (Figure 4). 


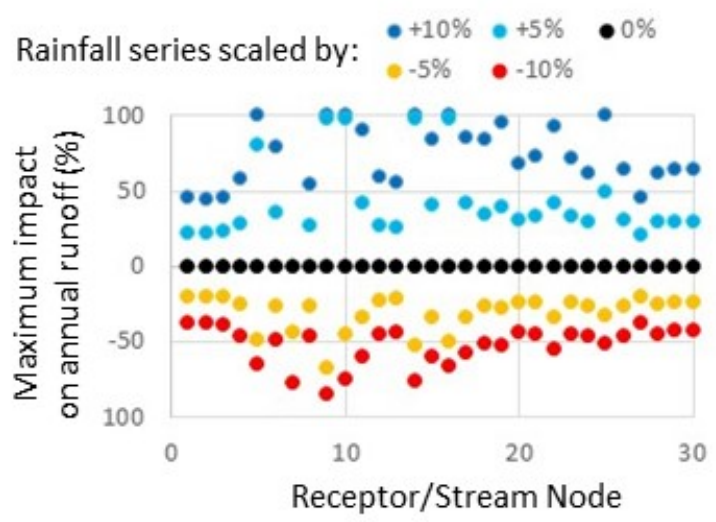

Figure 5. Maximum impact on annual runoff from scaled changes in future rainfall

(note that changes greater than $100 \%$ are shown as $100 \%$ )

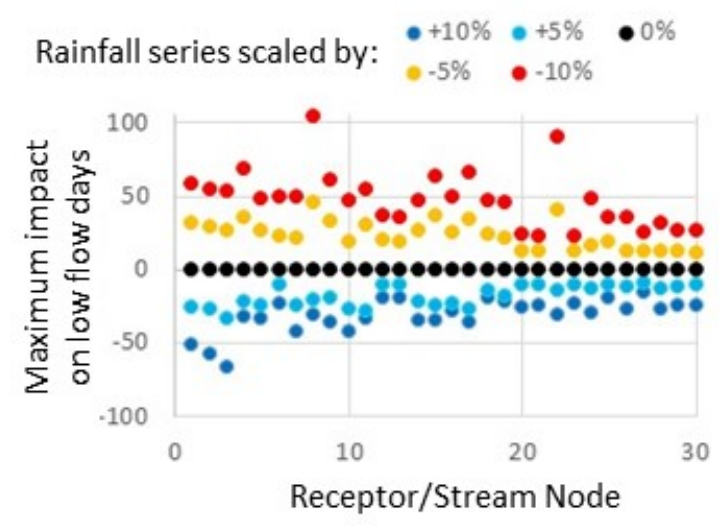

Figure 6. Maximum impact on low flow from scaled changes in future rainfall
Figure 7 shows the modelled maximum ACRD impact at Node 14 for a given future climate that is $10 \%$ drier, $5 \%$ drier, $5 \%$ wetter and $10 \%$ wetter, for the proposed mine footprint and a three times larger mine footprint (the latter to explore larger proposed developments). For annual runoff, the maximum ACRD impact is slightly greater for a drier future climate series compared to a wetter future climate series (Figure 7a). However, this difference in the ACRD maximum annual runoff impact is relatively small for the different climate futures (a difference of less than $2 \%$ for a $10 \%$ wetter future versus $10 \%$ drier future) and much smaller than the potential impact from climate change alone (Figure 5). Figure $7 \mathrm{~b}$ shows that for a three times larger mine footprint, the ACRD maximum annual runoff impact is comparable with the impact from a $10 \%$ reduction in future mean annual rainfall. The difference between ACRD impact evaluated using different rainfall futures also becomes larger (a difference in ACRD impact of about $10 \%$ for a $10 \%$ wetter future versus $10 \%$ drier future). Figures $7 \mathrm{c}$ and $7 \mathrm{~d}$ show that, for the analysis here, the ACRD impact on low flow is smaller when evaluated for both wetter and drier futures. The ACRD maximum low flow impact for simulations with climate futures of $-10 \%$ wetter to $10 \%$ drier ranges from 4 to 9 more low flow days for the proposed mine footprint (Figure 7c), and 19 to 27 more low flow days for three times larger mine footprint (Figure 7d).

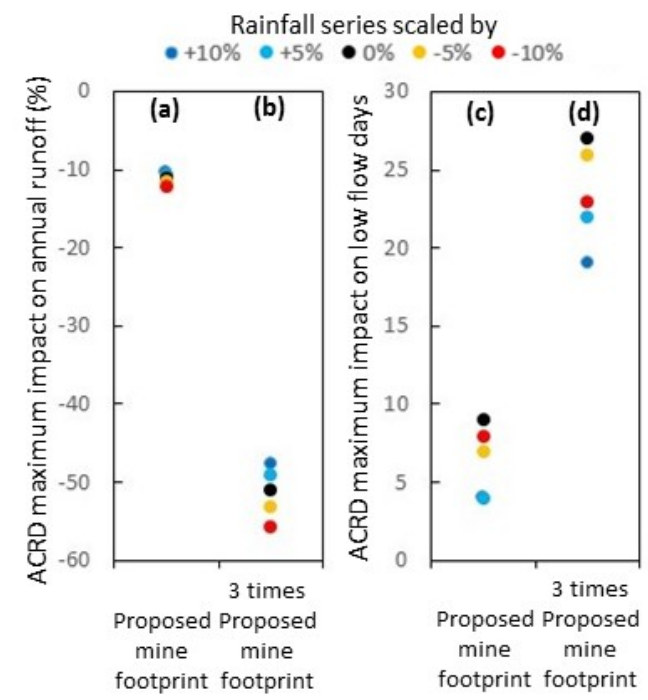

Figure 7. ACRD maximum impact at Node 14 for annual runoff for (a) proposed mine footprint and

(b) three times larger mine footprint, and ACRD maximum impact on low flow days for (c) proposed mine

footprint and (d) three times larger mine footprint.

\section{IMPACT OF COAL MINING DEVELOPMENT IN THE CONTEXT OF HYDROCLIMATE VARIABILITY}

The influence of hydroclimate variability on the maximum ACRD impact, particularly the rainfall series when the mine footprint is large, is investigated using stochastic rainfall series. One hundred stochastic replicates of 90 years of daily rainfall are generated to represent the 2013-2102 rainfall. The stochastic climate library method (https://toolkit.ewater.org.au/Tools/SCL) is used to generate multi-site daily rainfall. To reduce computational time and to realistically model the spatial rainfall correlations, stochastic daily rainfall is generated for 21 points, which is then interpolated to provide stochastic rainfall data for the 156 grid cells for hydrological modelling. The stochastic model is parameterised to reproduce the characteristics of the 19232012 rainfall series. The stochastic data generation is described in detail in Fu et al. (2017), which compares several stochastic climate models and shows that the SCL can reproduce the observed rainfall characteristics. 
Figures 8 and 9 show the range of maximum ACRD impact on annual runoff and on low flow respectively modelled using the 100 stochastic rainfall series. The plots indicate that the sequence of future rainfall can significantly influence the maximum ACRD impact. The maximum ACRD impact on annual runoff at Node 14 ranges from $10 \%$ to $18 \%\left(10^{\text {th }}\right.$ percentile and $90^{\text {th }}$ percentile values) (Figure 8$)$ and the maximum ACRD impact on low flow at Node 14 ranges from 2 to 5 more days with runoff less than the $5^{\text {th }}$ percentile value (Figure 9). This difference in the modelled maximum ACRD impact using different future stochastic rainfall series is much greater than the difference in modelled maximum ACRD impact for a given sequence with different mean annual rainfalls (as presented in Section 3).

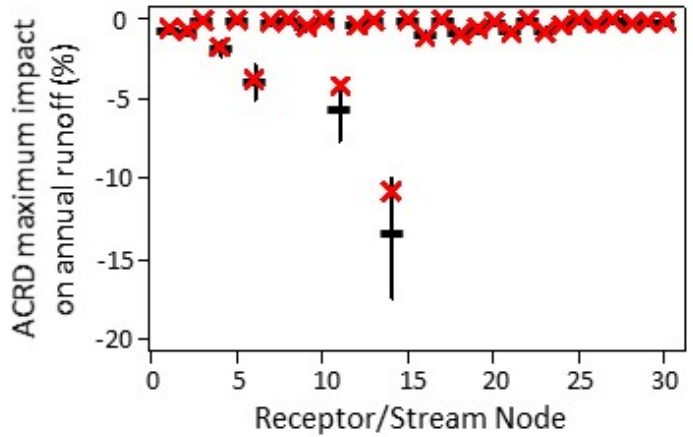

Figure 8. Distribution of ACRD maximum impact on annual runoff modelled using 100 stochastic replicates (plots show median and $10^{\text {th }}$ and $90^{\text {th }}$ percentile values, the red crosses show results when the 1923-2012 rainfall sequence is used (as in Figure 3)).

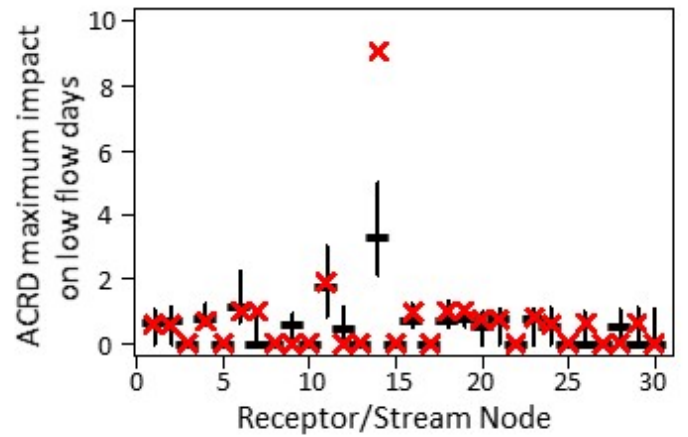

Figure 9. Distribution of ACRD maximum impact on low flow days modelled using 100 stochastic replicates (plots show median and $10^{\text {th }}$ and $90^{\text {th }}$ percentile values, the red crosses show results when the 1923-2012 rainfall sequence is used (as in Figure 4)).

As the ACRD impact is modelled as a reduction in the simulated runoff, the maximum ACRD impact on annual runoff will be greater if the annual runoff is high when the mine footprint is large. This is illustrated, for Node 14, in Figure 10 which shows that the maximum ACRD impact occurs when the mine footprint is large, and in Figure 11 which shows a strong correlation between maximum ACRD impact on annual runoff versus the annual rainfall or runoff in the year of maximum impact.

The simulations here also show that the modelled maximum ACRD impact on annual runoff using the 19232012 data sequence to represent the 2013-2102 future climate is at the low end ( $20^{\text {th }}$ percentile value) of the distribution of modelled ACRD impact with the stochastic future climate series (Figure 8). The maximum ACRD impact on low flow shows an opposite result, with the modelled maximum ACRD impact using the 1923-2012 data sequence being at the high end (greater than the $90^{\text {th }}$ percentile value) of the distribution of modelled ACRD impact with the stochastic future climate series (Figure 9). This is because the annual rainfall and runoff in the 1923-2012 series when the mine footprint is large are in the drier part of the stochastic runoff distribution, resulting in smaller ACRD impact on annual runoff and larger ACRD impact on low flow because there are more low flow days when runoff is low. It is not possible to formulate the exact relationship because the maximum ACRD impact is dependent on both the rainfall or runoff and the mine footprint in the different years. It is more difficult to model and interpret the impact on low flow (compared to flow volumes) because it is influenced by low runoff thresholds and non-linear rainfall-runoff and subsurface storage lag relationships. The assessment of low flow impact can benefit with model parameterisation that specifically targets low flows, better knowledge and more data, and hydrological modelling that explicitly considers surface and groundwater interactions.

\section{CONCLUSION}

The impact of climate change on runoff, even for a change in mean annual rainfall of $5 \%$, is considerably greater than the impact of coal mine development in the Gloucester subregion. The impact of coal resource development, relative to the impact from potential climate change, may be higher in regions with more significant developments, particularly in local areas immediately downstream of large mine footprints.

Using different future rainfall averages (to represent plausible impact of climate change on mean annual rainfall) can give different results in the modelled ACRD impact. The differences in the modelled ACRD impact, for different given future rainfall averages, are relatively small but not insignificant. In the Gloucester subregion, the difference in the modelled ACRD impact at Node 14 (where the impact is greatest) is less than 
$2 \%$ for a $10 \%$ wetter future versus a $10 \%$ drier future, but this difference will be greater in bioregions where the mine footprint is larger. The ACRD impact is higher when modelled using a drier future.

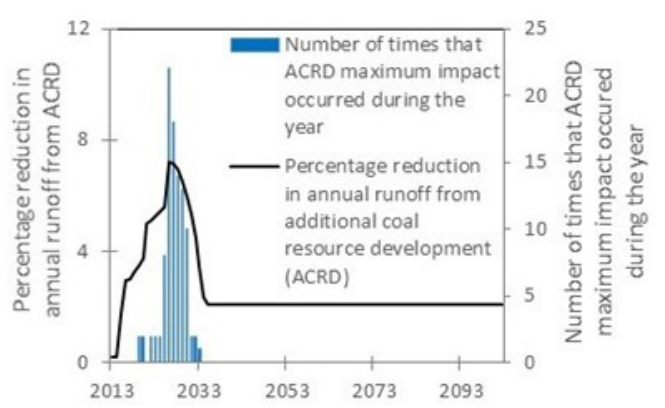

Figure 10. Number of times (in the 100 simulations) that the maximum ACRD impact on annual runoff at Node 14 occurred during the different years.

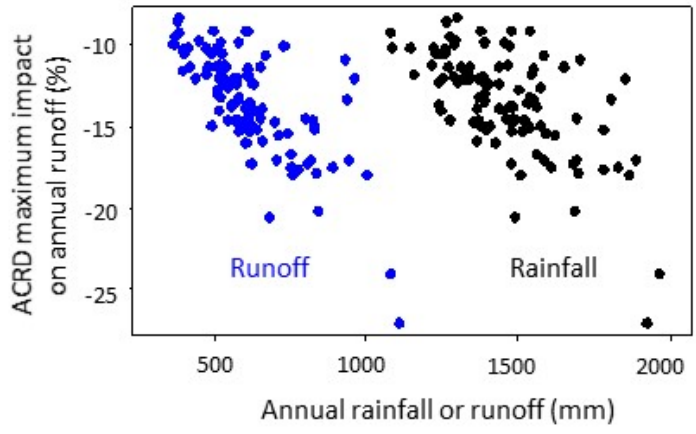

Figure 11. Maximum ACRD impact on annual runoff at Node 14 versus annual rainfall or runoff in the year of maximum impact.

The sequencing of hydroclimate series (hydroclimate variability), particularly the rainfall when the mine footprint is large, significantly influences the modelled maximum ACRD impact, and much more so than the future mean annual rainfall. If the rainfall is high in the period when the mine footprint is largest, the modelled maximum impact on volumetric and high flow hydrological variables will be higher, and the modelled maximum impact on low flow hydrological variables will be lower. For the Gloucester subregion, the maximum ACRD impact on annual runoff at Node 14 ranges from $10 \%$ to $18 \%\left(10^{\text {th }}\right.$ to $90^{\text {th }}$ percentile value) and the maximum ACRD impact on low flow ranges from 2 to 5 more days with runoff less than the $5^{\text {th }}$ percentile value, for simulations using 100 stochastic rainfall series.

In summary, (i) climate change impact is likely to be greater than ACRD impact except in local areas immediately downstream of large mine footprints, (ii) the difference in maximum ACRD impact modelled using future rainfall series with different long-term means (climate change) is relatively small, but can be significant where mine footprints are large, and (iii) the rainfall sequence or amount in the period when the mine footprint is large (hydroclimate variability) can significantly influence the modelled maximum ACRD impact. The results from this study indicate that detailed analysis of ACRD impact where proposed development is large should take into account climate change and hydroclimate variability, particularly the relative and combined impact from climate change and coal resource development, and the rainfall sequencing when the mine footprint is large.

\section{ACKNOWLEDGMENTS}

The Bioregional Assessment Programme is a joint initiative of the Department of Environment and Energy, the Bureau of Meteorology, CSIRO and Geoscience Australia. This study, which explores the influence of climate change and hydroclimate variability on the Bioregional Assessment modelling of coal resource development impact on runoff, is carried out with CSIRO strategic funds.

\section{REFERENCES}

Barrett DJ, Couch CA, Metcalfe DJ, Lytton L, Adhikary DP and Schmidt RK (2013). Methodology for bioregional assessments of the impacts of coal seam gas and coal mining development on water resources. A report prepared for the Independent Expert Scientific Committee on Coal Seam Gas and Large Coal Mining Development through the Department of the Environment and Energy.

Chiew FHS (2006). Estimation of rainfall elasticity of streamflow in Australia. Hydrological Sciences Journal, 51, 613-625, http://dx.doi.org/10.1623/hysj.51.4.613.

Chiew FHS, Teng J, Vaze J, Post DA, Perraud J-M, Kirono DGC and Viney NR (2009). Estimating climate change impact on runoff across south-east Australia: method, results and implications of modelling method. Water Resources Research, 45, W10414, http://dx.doi.org/10.1029/2008WR007338.

Fu G, Chiew FHS and Shi X (2017). Generation of multi-site stochastic daily rainfall with four weather generators: A case study of Gloucester catchment in Australia. Theoretical and Applied Climatology. In Review.

Vaze J, Viney N, Stenson M, Renzullo L, Van Dijk A, Dutta R, et al. (2013). The Australian Water Resource Assessment System (AWRA). Proceedings of the $20^{\text {th }}$ International Congress on Modelling and Simulation (MODSIM 2013), Dec 2013, Adelaide, Australia.

Zhang YQ, Viney NR, Peeters LJM, Wang B, Yang A, Li LT, McVicar TR, Marvanek SP, Rachakonda PK, Shi XG, Pagendam DE and Singh RM (2016). Surface water numerical modelling for the Gloucester subregion. Product 2.6.1 for the Gloucester subregion from the Northern Sydney Basin Bioregional Assessment. Department of the Environment and Energy, Bureau of Meteorology, CSIRO and Geoscience Australia. 